\title{
IMPLICACIONES BIOETICAS Y BIOJURIDICAS DE LA OBJECIÓN DE CONCIENCIA INSTITUCIONAL CON RELACIÓN AL ABORTO EN EL ORDENAMIENTO JURÍDICO COLOMBIANO
}

\author{
Amparo de Jesús Zárate Cuello*
}

Fecha de recepción: Octubre 15 de 2010

Fecha de aceptación: Enero 20 de 2010

Artículo de reflexión

\begin{abstract}
Resumen
El comienzo de la vida humana se encuentra en vilo en Colombia, ante la ratificación del Protocolo Facultativo sobre la eliminación de todas las formas de discriminación contra la mujer, adoptada por la Asamblea General de las Naciones Unidas de 1999, ratificada en el año de 2005. El tema se desarrolla en dos Sentencias, la primera, C-355 de 2006 despenaliza el aborto en tres situaciones excepcionales: Violación, enfermedad de la madre y malformación del feto. La segunda, T-388 de 2009 abarca la objeción de conciencia, que solamente es reconocida a las personas naturales; afirmando el máximo Tribunal Constitucional que no es un derecho del cual sean titulares las personas jurídicas o el Estado, limitando a las clínicas, hospitales y centros de salud que presenten objeción de conciencia para la no realización de la práctica del aborto.

El no cumplimiento de esta declaración ha producido sanciones a las instituciones sanitarias privadas por el no acatamiento de los efectos erga ommes de las sentencias proferidas por la Corte Constitucional; estas instituciones reclaman objeción de conciencia institucional por su ideario y creencias religiosas.
\end{abstract}

Estos criterios tienen implicaciones bioéticas y biojurídicas frente a la interpretación pluralista de orden filosófico, religioso y jurídico del artículo 18 de la Carta Política; el cual, garantiza la libertad de conciencia en nuestro Estado Social de Derecho y, es el legislador quien debe reasumir su competencia a través del bioderecho.

\section{Palabras clave}

Derecho a la Vida, Aborto, Objeción de Conciencia Institucional, Derechos Humanos, Derechos Sexuales y Salud Reproductiva, Corte Constitucional, Congreso, Corporaciones, Funcionarios Públicos, Bioética, Bioderecho, Eugenesia Negativa.

\footnotetext{
Docente T. C. UMNG. Abogada Universidad Libre de Colombia. C- Ph.D Filosofía del Derecho, Universidad Complutense de Madrid. DEA. Suficiencia Investigadora en Filosofía del Derecho UNED Madrid. Experta en Derecho de Familia, Derecho Administrativo, Promoción en Salud y Desarrollo Humano. Asesora Legislativa e Investigadora en Bioética. Investigadora Línea de investigación Bioética y Derecho, Derecho Penal y Sociología Jurídica, Grupo Derecho Público, Facultad de Derecho, UMNG. amparo.zarate@unimilitar.edu.co; amparozaratecuello@gmail.com
} 


\title{
BIOETHICS AND BIO LEGAL IMPLICATIONS OF THE INSTITUTIONAL OBJECTION REGARDING THE LEGAL ABORTION IN COLOMBIA
}

\begin{abstract}
The beginning of human life in Colombia is not clear because of the ratification of the Facultative Protocol about the elimination against women adopted by the United Nation Assembly in 1999, ratifies in 2005 and the C-355 Sentences in 2006, that legalizes abortion practices in three special cases: violation, mother's sickness and letal malformation.

In the same sense the T-388 sentence of year 2009 T-388 about conscientious objection wich is recognized only to natural persons but not to legal entities or to the state according to the Constitutional Court which determines that hospitals and health care institutions can make use of conscientious objection for the poor application of abortion practices. The non compliance with the lans has become in sanctions to the private sanitary institutions by the non obedience to the erga ommes effectes uttered by the Constitutional court, which claims for institutional conscientious objection and religion beliefs rights these concepts generate bio - ethical and bio - juridical implications because of the pluralistic interpretation of philosophical, legal and religious aspects of Article 18 of the national constitution that guarantees the conscience freedom of our social state of law and finally is the Legislator wo has to decide according to the biojuridical tools.
\end{abstract}

\section{Key words}

Right to Life, Abortion, Institutional Conscientious Objection, Human Rights, Sexual Rights and Reproductive Health, Constitutional Court, Congress, Corporations, Public Officials, Bioethics, Bio-law, Negative Eugenics.

\section{IMPLICAÇÕES BIOÉTICAS E BIOJURÍDICAS DA OBJEÇÃO DE CONSCIÊNCIA INSTITUCIONAL EM RELAÇÃO AO ABORTO NA ORDEM JURÍDICA COLOMBIANA}

\begin{abstract}
Resumo
O início da vida humana se encontra indeciso na Colômbia diante da ratificação do Protocolo Facultativo sobre a eliminação de todas as formas de discriminação contra a mulher, adotado pela Assembléia Geral das Nações Unidas de 1999, ratificada em 2005. O tema se desenvolve em duas Sentenças. A primeira, a C-355 de 2006, descriminaliza o aborto em três situações excepcionais: estupro, doença da mãe e malformação do feto; a segunda, a T-388 de 2009, abrange a objeção de consciência, que somente é reconhecida às pessoas naturais, afirmando o Superior Tribunal Constitucional que não é um direito do qual sejam titulares as pessoas jurídicas ou o Estado, limitando às clinicas, hospitais e centros de saúde a apresentação de objeção de consciência para a não realização da pratica do aborto.

O não cumprimento desta declaração tem causado sanções às instituições sanitárias particulares pelo não acatamento dos efeitos erga ommes das sentenças proferidas pela Corte Constitucional; estas instituições reivindicam objeção de consciência institucional por sua ideologia e crenças religiosas.
\end{abstract}


Estes critérios têm implicações bioéticas e biojurídicas diante da interpretação pluralista de ordem filosófica, religiosa e jurídica do artigo 18 da Carta Política, que garante a liberdade de consciência em nosso Estado Social de Direito, e é o legislador quem deve reassumir sua competência através do biodireito.

\section{Palavras-chave}

Direito à Vida, Aborto, Objeção de Consciência Institucional, Direitos Humanos, Direitos Sexuais e Saúde Reprodutiva, do Tribunal Constitucional, o Congresso, corporações, os funcionários públicos, a Bioética, Bio-lei, ea eugenia negativa.

\section{INTRODUCCIÓN}

El presente artículo surge ante los polilemas suscitados por la interpretación semántica del artículo 18 de la libertad de conciencia, consagrada en el ordenamiento jurídico constitucional por parte de las instituciones prestadoras de salud de orden privado y/o confesional, el proyecto de ley que presentará en el periodo de 2011 por el Procurador General de la Nación, el planteamiento jurisprudencial del Magistrado de la Corte Constitucional José Ignacio Pretelt, la academia, representada por el Instituto de Bioética de la Universidad Javeriana, Universidad del Rosario y Militar Nueva Granada, en Foro organizado por la Asociación Nacional de Bioética ANALBE, en la Universidad Militar Nueva Granada el 23 de septiembre de 2010, sobre "la objeción de conciencia institucional", con el propósito de dar a conocer la problemática bioética y por ende una respuesta desde el bioderecho a los estamentos implicados en el tema, a las sociedades científicas, al colectivo social y al legislador colombiano.

Evolución histórica y jurisprudencial sobre la despenalización del aborto en Colombia y la denegación de la aplicación de la objeción de conciencia institucional.

La práctica del aborto en Colombia es un tema consuetudinario ante la utilización de diferentes maneras para evitar los embarazos no deseados.

Son las feministas y los grupos de mujeres quienes históricamente han puesto el tema en la escena pública del país desde diferentes ámbitos y posiciones: libre opción a la maternidad, interrupción libre de preñez, derechos sexuales y derechos reproductivos, despenalización o legalización del aborto. (CARDONA, C. E.)

En efecto, el comienzo de la vida humana se encuentra actualmente en vilo en Colombia, desde la ratificación del Protocolo Facultativo de la Convención sobre la eliminación de todas las formas de discriminación contra la mujer, adoptada por la Asamblea General de las Naciones Unidas de la CEDAW del año de 1.999, que hizo trámite en el Congreso de Colombia; que ya fue sancionado por el Presidente De La República; y concomitantemente, la demanda de inconstitucionalidad del artículo 122 del Código Penal contentivo en la Ley 599 del 2.000 que cursó en la Corte Constitucional, impetrada por la abogada MÓNICA ROA, que confluyó en la despenalización de el delito de aborto en Colombia para tres situaciones específicas: En caso de acceso carnal o acto sexual sin consentimiento, abusivo o de inseminación artificial o transferencia de óvulo fecundado no consentidas, o de incesto, malformaciones de feto incompatibles con la vida y cuando se encuentre en peligro o riesgo la salud de la madre.

A manera de antecedente, es menester resaltar, que la génesis del aborto, data desde hace noventa y cinco años con la creación de los movimientos para el Control de la Natalidad generados por Margaret Sanger. ${ }^{1}$ Las herederas

\footnotetext{
1 Margaret Sanger, feminista, enfermera de profesión, quien en 1.914 fundó La Mujer Rebelde, una revista femenina mensual que promovía el control de la natalidad.Para 1.921 fundó la Liga Americana para el Control de Natalidad, organizó la primera Conferencia Mundial
} 
de la filosofía de Margaret Sanger, lograron hacer parte del Comité de la CEDAW de las Naciones Unidas compuesta por 23 mujeres de distintas nacionalidades, quienes expidieron el Protocolo Facultativo en mención, cuya misión entre otras como la de perspectiva de género, es la de proponer la globalización del aborto y de lograr despenalizarlo en aquellos países que aún protegen los derechos del nasciturus.

Colombia es signataria de la Convención sobre la Eliminación de todas las formas de Discriminación Contra la Mujer, aprobada mediante Ley 51 de 1.981 ratificada el 19 de enero del 1.982 y el Protocolo fue firmado en tanto el 10 de diciembre de 1.999. Al sancionar el Presidente de la República el proyecto de Ley 012 de 2.004 Cámara, contentivo del Protocolo referenciado, obliga al país a ajustarse a las decisiones de la CEDAW a partir de la fecha en que se perfeccione el vínculo internacional respecto del mismo, de conformidad con lo dispuesto en el artículo 1 de la Ley 7 de 1.944 (Articulo 2 Proyecto de Ley 012-2.004). Es decir, su carácter es jurídicamente vinculante y le dará al Comité de La CEDAW amplia potestad sobre Colombia como Estado parte, constituyéndose sus decisiones en bloque de constitucionalidad quedando incurso en la pérdida de la soberanía Nacional para esos efectos.

sobre Población, celebrada en Ginebra en el año 1.927 y fue precursora de la Federación de Planificación Familiar (1.942). Nació dentro de una familia numerosa Irlandesa; viendo que su madre quedaba debilitada cada vez que tenía un hijo, creció con la obsesión de liberar a la mujer de la maternidad con el fin de equiparar la igualdad de derechos del hombre. Sus frases más célebres fueron las siguientes:"Lo más misericordioso que una familia numerosa puede hacer con uno de sus miembros más pequeños es matarlo". "Más hijos para los capacitados; menos hijos para los incapacitados, ésa es la esencia del control de la natalidad" Incapacitados para ella eran negros y latinos. "No queremos que nadie se entere de que queremos eliminar a la población negra" Margaret Sanger, citado en Madeline Gray, Margaret Sanger: A Biography (Nueva York: Marek, 1979), 326; Margaret Sanger, Woman and the New Race (Nueva York: Brentano's, 1.920. Reimpr. : Geo. W. Halter, 1928); Margaret Sanger, The Birth Control Review, mayo de 1919
A futuro inmediato se consideraría como un atentado a la discriminación de la mujer el hecho de penalizar el aborto en Colombia, ya que para el año de 1.999 el Comité de La CEDAW en el informe sobre Colombia manifiesta su gran preocupación porque el aborto sea sancionado como un hecho punible y de la misma manera "solicita al gobierno de Colombia para que tome medidas inmediatas y así derogar la Ley Penal", en ese sentido; lo que se observa con respecto a la demanda instaurada por la abogada Mónica Roa, quien fundamentó la despenalización del aborto precisamente en los postulados del Protocolo Facultativo de La CEDAW, antes de que el Congreso de Colombia lo ratificara, infiriendo que en efecto se ratificaría, con palmaria manipulación del lenguaje en la interpretación semántica del alcance y contenido que la Asamblea Nacional Constituyente de 1.991 plasmó en la Carta Política Colombiana en el acápite de "Normas Constitucionales violadas", para ajustarlas a los cambios culturales; con una connotación distinta a la expresada en los derechos fundamentales, atinentes a la obligación del Estado de cumplir con los tratados internacionales de derechos humanos ratificados por Colombia (Artículo 93(2) C.P.), el derecho a la vida salud e integridad (Artículos 11, 12, 43 y 49 C.P.), igualdad y a estar libre de discriminación (Artículo 13 C.P.), dignidad humana, autonomía reproductiva y libre desarrollo de la personalidad (Preámbulo de la CP., Artículos 1, 16 y 42 C.P.).

No obstante, el Procurador General de la Nación de ese entonces Edgardo José Maya Villazón, procedió a rendir concepto ante la Corte Constitucional en la demanda de inconstitucionalidad contra el artículo 122 de la Ley 599 de 2.000 "por la cual se expide el Código Penal, manifestando que el aborto en circunstancias especiales es constitucional y solicitó a la Corte:

“a. Declarar la exequibilidad del artículo 122 de la Ley 299 de 2.000, bajo la condición de que no sea incluida como conducta objeto de penalización la interrupción voluntaria del embarazo en los casos de:

Concepción no consentida por la mujer. 
En embarazos con grave riesgo para la vida o la salud física o mental de la mujer.

Establecimiento médico de la existencia de enfermedades o disfuncionalidades del feto que le hagan inviable.

b. Como consecuencia derivada de lo anterior declarar la inexequibilidad del Artículo 124 de la ley 599 de 2000". (MAYA: 2005)²

Finalmente, el Procurador:

Insta al Congreso a desarrollar una legislación sobre derechos reproductivos de la mujer, con observancia de los tratados y las recomendaciones de los organismos internacionales de protección de los derechos humanos que incluya políticas preventivas de educación orientación y asistencia especialmente dirigidas a la población más vulnerable. (MAYA: 2005)

De igual forma la Conferencia Episcopal Colombiana emitió un comunicado en referencia al debate suscitado en la Corte, manifestando:

"Nuestro ordenamiento jurídico constitucional reconoce el carácter inviolable del derecho a la vida, así como el principio del respeto a la dignidad humana. De conformidad con los tratados internacionales, la vida ha de ser respetada desde el momento de la concepción. Este principio ha de orientar toda acción del Estado y promover el absoluto de lo humano. Permitir que el aborto sea despenalizado, en algunos supuestos, es legitimar al Estado para

2 El artículo 124 de la Ley 599 de 2.000 contempla: "Articulo 124. Circunstancias de atenuación punitiva. La pena señalada para el delito de aborto se disminuirá en las tres cuartas partes cuando el embarazo sea resultado de una conducta constitutiva de acceso carnal o acto sexual sin consentimiento. Abusivo, de inseminación artificial o transferencia de óvulo fecundado no consentidas. Parágrafo En los eventos del inciso anterior, cuando se realice el aborto en extraordinarias condiciones anormales de motivación, el funcionario judicial podrá prescindir de la pena cuando ella no resulte necesaria en el caso concreto." que renuncie a cumplir efectivamente sus deberes frente a la vida humana. Condenamos la discriminación contra la mujer. Proclamamos y defendemos los derechos humanos fundamentales que son inherentes a toda persona humana. Defendemos tanto al niño no nacido como a la madre.

Rechazamos la cultura de la muerte que ha legitimado la idea de disponer de la vida humana como si se tratara de una cosa. Reiteramos que no hay razones legitimas para eliminar la vida humana no nacida, que corresponde a un ser distinto de la madre, que empieza a vivir su propia vida en el momento de la concepción y que por tener la condición de ser humano ha de ser respetado conforme a su dignidad.

A una recta razón, y con mayor fuerza a una conciencian iluminada por la fe cristiana, le debe brotar con facilidad el rechazo al aborto por ser el asesinato de un ser inocente que no es culpable de nada, que no tiene ninguna posibilidad de defensa por sí mismo, ni siquiera puede gritar, a lo sumo gime en el acto de morir.

El aborto es un "crimen abominable" que viola el derecho fundamental a la vida del ya engendrado y no nacido, y configura un grave desorden moral que involucra a quienes a ciencia y conciencia intervienen en este hecho.

Nunca como en el tiempo presente se ha hablado tanto de los derechos humanos, pero nunca como ahora se ha violentado tan impunemente los derechos del hombre que todavía está en el seno materno.

El aborto no es asunto de vida privada por que conlleva intereses y derechos de otro. El aborto provocado no es sólo un asunto privado de los padres, si no que afecta directamente a la unidad de la especie humana. Los legítimos derechos de la mujer sobre su fuero terminan donde comienzan los derechos del niño concebido en su vientre.

"Las leyes que legitiman la eliminación directa de seres humanos inocentes están en contradicción total e inconciliable con el derecho inviolable a 
la vida... Leyes de este tipo no solamente no crean ninguna obligación para la conciencia sino que, por el contrario, generan una grave y precisa obligación de oponerse a ellos a través de la objeción de conciencia..." (JUAN PABLO II: Evangelium Vitae)

Esperamos que las autoridades públicas que participan en el debate sobre despenalización del aborto, actúen en el marco del ordenamiento jurídico, tanto constitucional como internacional, $y$ al hacerlo obren libremente y en conciencia. Exhortamos a los órganos del Estado a promover el eficaz cumplimiento de los derechos de las mujeres y a estudiar medidas alternativas que las protejan en las situaciones difíciles que puedan vivir durante su embarazo. La sociedad entera debe estar abierta a ayudar a las madres y acoger aquellos niños que nacen desprotegidos e indefensos. Pedimos a todos los católicos defender el precepto "no mataras" que indica tanto el límite de lo que no puede ser transgredido en el ámbito social, como la responsabilidad que tiene todo hombre y toda mujer sea o no creyente, de respetar la vida humana. Expresamos nuestro apoyo a todas las personas y organizaciones que en este momento crucial de la historia colombiana defienden con valor la vida, reclamando el respeto a los derechos fundamentales de toda persona humana". (CASTRO: 2007: 83-85)

Como conducta punible, el aborto ha sido analizado en tres sentencias de la Corte Constitucional. El alto tribunal ha considerado que la penalización del aborto se ajusta a los parámetros constitucionales, toda vez bajo el amparo de las libertades no es procedente legitimar conductas que conduzcan a la privación de la vida humana durante el proceso de gestación. (CORTE CONSTITUCIONAL COLOMBIANA: 1994) Esta doctrina fue reiterada al analizar la constitucionalidad de aquellas normas que penalizan a la mujer que aborta como consecuencia de acceso carnal o acto sexual sin consentimiento, abusivo, de transferencia de óvulo fecundado no consentida o de inseminación artificial si consentimiento de la mujer. (CORTE CONSTITUCIONAL COLOMBIANA: 1999) En opinión de la Corte la defensa de la vida humana en todos sus estadios es obligación y responsabilidad de las Autoridades. (DEFENSORÍA DEL PUEBLO: 125)

La Corte Constitucional, estuvo atiborrada de firmas donde se manifestó el querer del pueblo Colombiano con un NO rotundo al aborto. (ZÁRATE: 2005) No obstante, mediante la Sentencia C-355-06 de fecha 10 de Mayo de $2.006^{3}$, la Corte Constitucional declaró exequible el artículo 122 del Código Penal Colombiano y a su vez eliminó la pena de uno a tres años que contempla el Código Penal Colombiano para el delito de aborto, pero solo para las tres situaciones especificas contempladas en el fallo judicial, es decir que para los demás casos se sigue configurando el delito y por consecuente seguiría penalizado. ${ }^{4}$

La mencionada despenalización del aborto causó un gran impacto en la sociedad colombiana y preocupación por el futuro de la familia como célula fundamental de la sociedad, el de la soberanía Nacional y el camino a las prácticas Eugenésicas, priorizando en este caso la eugenesia negativa.

Cabe mencionar la distinción que estableció la Corte Constitucional entre la vida como un bien

3 La sentencia de la Corte Constitucional en su parte resolutiva contempla: "Declarar EXEQUIBLE el artículo 122 de la Ley 599 de 2000, en el entendido que no se incurre en delito de aborto, cuando con la voluntad de la mujer, la interrupción del embarazo se produzca en los siguientes casos: (i) Cuando la continuación del embarazo constituya peligro para la vida o la salud de la mujer, certificada por un médico; (ii) Cuando exista grave malformación del feto que haga inviable su vida, certificada por un médico; y, (iii) Cuando el embarazo sea el resultado de una conducta, debidamente denunciada, constitutiva de acceso carnal o acto sexual sin consentimiento, abusivo o de inseminación artificial o transferencia de óvulo fecundado no consentidas, o de incesto." Corte Constitucional Colombiana. Sentencia C-355-06 de 10 de Mayo de 2006.

4 "La despenalización se aplica en tres casos especiales: cuando la mujer haya sido objeto de violación, cuando haya una malformación grave en el feto o cuando el embarazo revista riesgo para la madre. En esos tres casos, el Código Penal preveía una reducción de las tres cuartas partes de la condena. 
constitucionalmente protegido y el derecho a la vida como un derecho subjetivo de carácter fundamental. (CORTE CONSTITUCIONAL: C-355-06)

\section{Considera la Corte Constitucional:}

"Conforme a lo expuesto, la vida y el derecho a la vida son fenómenos diferentes. La vida humana transcurre en distintas etapas y se manifiesta de diferentes formas, las que a su vez tienen una protección jurídica distinta. El ordenamiento jurídico, si bien es verdad, que otorga protección al nasciturus, no la otorga en el mismo grado e intensidad que a la persona humana. Tanto es ello así, que en la mayor parte de las legislaciones es mayor la sanción penal para el infanticidio o el homicidio que para el aborto. Es decir, el bien jurídico tutelado no es idéntico en estos casos y, por ello, la trascendencia jurídica de la ofensa social determina un grado de reproche diferente y una pena proporcionalmente distinta.

La decisión se produce luego de dos días de sesiones plenas de la Corte, de las que se ausentó el Presidente del Tribunal, Jaime Córdoba Triviño, pues se declaró impedido al haber participado en la redacción de la norma demandada por la abogada Mónica Roa. No obstante, hay que aclarar que en los demás casos, el aborto sigue siendo ilegal. Roa, apoyada por la ONG Women's Link Worldwide (WLW), había presentado en abril del año anterior una demanda en la que además incluía las recomendaciones de dicha organización. El asunto generó toda una controversia nacional entre la Iglesia Católica y organizaciones conservadoras, que se oponen al aborto en cualquier caso, y sectores más liberales y feministas, que se pusieron a favor de la despenalización en casos especiales. En diciembre pasado, el alto tribunal constitucional se había declarado inhibido por supuestas fallas en la acción presentada por Roa, quien corrigió la demanda y la volvió a presentar a comienzos del presente año. Si hay malformaciones del feto o peligro para la madre, la corte sentenció que, para poder practicar el aborto, debe haberse expedido una certificación médica. En caso de abuso sexual, debe haber una denuncia ante las autoridades competentes o un concepto de una autoridad médica, como Medicina Legal." Corte Constitucional de Colombia despenaliza parcialmente el aborto 11 de mayo de 2006.

Cfr.: http://es.wikinews.org/wiki/Corte_Constitucional_ de_Colombia_despenaliza_parcialmente_el_aborto.
De manera que estas consideraciones habrán de ser tenidas en cuenta por el legislador, si considera conveniente fijar políticas públicas en materia de aborto, incluidas la penal en aquellos aspectos en que la Constitución lo permita, respetando los derechos de las mujeres". (CORTE CONSTITUCIONAL: C355-06)

Claramente se observa que La Corte Constitucional Colombiana acogió para este fallo los planteamientos de la CEDAW sobre la violencia basados en sexo y genero ${ }^{5}$, sobre el derecho a la salud sexual reproductiva, ${ }^{6}$ el derecho al

5 Es así como la CEDAW ha declarado, que "la violencia contra la mujer es una forma de discriminación que inhibe gravemente la capacidad de la mujer de gozar de derechos y libertades en pie de igualdad con el hombre". La Convención de Belém do Pará, en vigor desde el 5 de marzo de 1995 y para Colombia desde el 15 de diciembre de 1996 -Ley 248 de 1995-, es uno de los instrumentos más importantes para la protección de los derechos de las mujeres ante las diversas formas de violencia a que están sometidas en los diversos espacios de su vida. Ella ha determinado dos elementos que la hacen especialmente efectiva: una definición de violencia contra la mujer, que considera estos actos como violatorios de derechos humanos y las libertades fundamentales, tomando en cuenta los abusos que ocurren tanto en el ámbito público como en el privado; $y$, el establecimiento de la responsabilidad del Estado por la violencia perpetrada o tolerada por este dondequiera que ocurra.

6 También en el área de salud, se deben eliminar todas las barreras que impidan que las mujeres accedan a servicios, a educación e información en salud sexual y reproductiva. La CEDAW ha hecho hincapié en que las leyes que penalizan ciertas intervenciones médicas que afectan especialmente a la mujer, constituyen una barrera para acceder al cuidado médico que las mujeres necesitan, comprometiendo sus derechos a la igualdad de género en el área de la salud y violando con ello la obligación internacional de los Estados de respetar los derechos reconocidos internacionalmente Recomendación General No. 24, para el cumplimiento del artículo 12 de la Convención sobre la eliminación de todas las formas de discriminación contra la mujer -la mujer y la salud.

Respecto de los derechos sexuales y reproductivos, con fundamento en el principio de dignidad de las personas y sus derechos a la autonomía e intimidad, uno de sus componentes esenciales lo constituye el derecho de la mujer a la autodeterminación reproductiva y a elegir libremente el número de hijos que quiere tener y el 
libre desarrollo de la personalidad como límite a la libertad de configuración del Legislador en materia penal.

La perspectiva de género, es la de proponer la globalización del aborto y de lograr despenalizarlo en aquellos países que aún protegen los derechos del nasciturus.

En cuanto el derecho al libre desarrollo de la personalidad parte de una consideración de tipo axiológico: el principio de la dignidad humana y el marcado carácter libertario de la Carta de 1991.

Este derecho es entendido entonces, como la consecuencia necesaria de una nueva concepción que postula al Estado "como un instrumento al servicio del hombre y no al hombre al servicio del Estado". Bajo ésta nueva óptica la autonomía individual -entendida como la esfera vital conformada por asuntos que sólo atañen al individuo- cobra el carácter de principio constitucional que vincula a los poderes públicos, a los cuales les está vedada cualquier injerencia en este campo reservado, pues decidir por la persona supone "arrebatarle brutalmente su condición ética, reducirla a la condición de objeto, cosificarla, convertirla en un medio para los fines que por fuera de ella se eligen" Como ha afirmado la Corte Constitucional este derecho condensa la libertad in nuce, "porque cualquier tipo

intervalo entre ellos, como así lo han reconocidos las deferentes convenciones internacionales.

En conclusión, los derechos sexuales y reproductivos de las mujeres han sido finalmente reconocidos como derechos humanos, y como tales, han entrado a formar parte del derecho constitucional, soporte fundamental de todos los Estados democráticos.

Derechos sexuales y reproductivos que además de su consagración, su protección y garantía parten de la base de reconocer que la igualdad, la equidad de género y la emancipación de la mujer y la niña son esenciales para la sociedad y por lo tanto, constituyen una de las estrategias directas para promover la dignidad de todos los seres humanos y el progreso de la humanidad en condiciones de justicia social de libertad se reduce finalmente a ella". Se trata por lo tanto del derecho a la libertad general de actuación, que comprende no sólo los específicos derechos de libertad consagrados por la Constitución (libertad de cultos, de conciencia, de expresión e información, libertad de escoger profesión u oficio, libertades económicas, etc.) sino también el ámbito de autonomía individual no protegido por ninguno de estos derechos. (CORTE CONSTITUCIONAL: C 355-06)

Haciendo también acopio dentro de esta misma sentencia, del derecho a la autonomía individual señaladas en anteriores jurisprudencias de la misma Corporación. ${ }^{7}$

7 Ver entre otras las sentencias C-221/94, C-309/97 y T-516/98 de la Corte Constitucional Colombiana. En esta última se afirma lo siguiente: "La constitución opta por un orden jurídico que es profundamente respetuoso de la dignidad y la autonomía individuales (CP. art. $1^{\circ}$ y 16), por lo cual, en principio, no corresponde al Estado ni a la sociedad, sino a las propias personas, decidir la manera como desarrollan sus derechos y construyen sus proyectos de vida y sus modelos de realización personal". Aún más explícito en cuanto al referente axiológico del derecho, resulta el siguiente extracto de la sentencia T-67/97: "El núcleo del libre desarrollo de la personalidad se refiere entonces a aquellas decisiones que una persona toma durante su existencia y que son consustanciales a la determinación autónoma de un modelo de vida y de una visión de su dignidad como persona. En una sociedad respetuosa de la autonomía y la dignidad, es la propia persona quien define, sin interferencias ajenas, el sentido de su propia existencia y el significado que atribuya a la vida y al universo, pues tales determinaciones constituyen la base misma de lo que significa ser una persona humana. La Corte ha reconocido entonces en este derecho 'un contenido sustancial que se nutre del concepto de persona sobre el que se erige la constitución' por cuanto el artículo 16 de la Carta 'condensa la defensa constitucional de la condición ética de la persona humana, que la hace instancia suprema e irreductible de las decisiones que directamente le incumben en cuanto que gracias a ellas determina y orienta su propio destino como sujeto autónomo, responsable y diferenciado. En ese orden de ideas, se afirma en la sentencia C-616/97: "de cierto modo, puede decirse que la consagración del derecho al libre desarrollo de la personalidad viene a ser como el colofón o la decisión complementaria que el constituyente adoptó como garantía de las libertades religiosa, de pensamiento y opinión y de conciencia. 
Al decidir las Corte Constitucional la no penalización del aborto en cualquiera de los tres casos señalados con anterioridad, estipuló los parámetros básicos a seguir para cada uno de ellos; en el evento de que fuese por acceso carnal violento o acto sexual sin consentimiento, abusivo, el médico que lo practique queda amparado bajo el principio de la buena fe con la sola denuncia presentada por la solicitante. El proceso legal seguiría su curso y si más adelante se comprueba una falsa denuncia de violación, se configura un delito que compromete en mayor parte a la mujer. En cuanto a las malformaciones incompatibles con la vida $y$ cuando la continuación del embarazo constituya peligro para la vida o la salud de la mujer, se estima que se requerirán exámenes especializados certificados por el médico. La despenalización no convierte el aborto en una conducta obligada si no permitida, lo cual admite la objeción de conciencia por parte de los médicos, (DE BRIGARD: 2006: $1-8)^{8}$ pero no para personal administrativo .

8 Con respecto a la objeción de conciencia considera la Corte Constitucional Colombiana: "La objeción de conciencia no es un derecho del cual son titulares las personas jurídicas, o el Estado. Solo es posible reconocerlo a personas naturales, de manera que no pueden existir clínicas, hospitales, centros de salud o cualquiera que sea el nombre con que se les denomine, que presenten objeción de conciencia a la práctica de un aborto cuando se reúnan las condiciones señaladas en esta sentencia. En lo que respecta a las personas naturales, cabe advertir, que la objeción de conciencia hace referencia a una convicción de carácter religioso debidamente fundamentada, y por tanto no se trata de poner en juego la opinión del médico entorno a si está o no de acuerdo con el aborto, y tampoco puede implicar el desconocimiento de los derechos fundamentales de las mujeres; por lo que, en caso de alegarse por un médico la objeción de conciencia, debe proceder inmediatamente a remitir a la mujer que se encuentre en las hipótesis previstas a otro médico que si pueda llevar a cabo el aborto, sin perjuicio de que posteriormente se determine si la objeción de conciencia era procedente y pertinente, a través de los mecanismos establecidos por la profesión médica." Corte Constitucional Colombiana. Sentencia C-355-06.

9 En este sentido esta reglamentado por el articulo quinto del Decreto 4444 de 2006 que señala: "Con el fin de garantizar la prestación del servicio público esencial de salud, evitar barreras de acceso y no vulnerar los derechos fundamentales protegidos por la Sentencia C-355/06, la objeción de conciencia es una decisión individual y no institucional, que aplica exclusivamente a prestadores directos y no a personal administrativo." Decreto 4444 de 2006 Ministerio de la Protección Social. República de Colombia.
Aunque la Corte consideró que para todos los efectos jurídicos, las decisiones adoptadas en esta sentencia tienen vigencia inmediata y el goce de los derechos por esta protegidos no requiere de desarrollo legal o reglamentario alguno, incluyendo la aplicación del principio de favorabilidad, enfatizando que no obsta para que los órganos competentes, si lo consideran conveniente, expidan normas que fijen políticas públicas acordes con esta decisión.

Es así como el Ministerio de la Protección Social mediante el Decreto 4444 de 2006 Por el cual se reglamenta la prestación de unos servicios de salud sexual y reproductiva, para garantizar el "goce efectivo en condiciones de igualdad y de seguridad dentro del sistema de seguridad social en salud"; donde establece disponibilidad en al acceso a la interrupción voluntaria del embarazo en todo el territorio nacional para todas las mujeres, independientemente de su capacidad de pago y afiliación al Sistema General de Seguridad Social en Salud-SGSSS, y en subsecuente que ninguna entidad deberá poner trabas administrativas que posterguen la prestación del servicio, además del establecimiento del las normas técnicas y de financiación para los procedimientos, el Decreto también prohíbe las prácticas discriminatorias hacia la mujer, los médicos y las entidades prestadoras de los servicios de Salud, por situaciones derivadas de la práctica o no del procedimiento, por objeción o no objeción de conciencia. (MINISTERIO: 2006) Al respecto la Corte Constitucional en Sentencia T-209-08 afirmó:

La objeción de conciencia no es un derecho absoluto. Los profesionales de la salud deben atender las solicitudes de interrupción de embarazo en forma oportuna de conformidad con la sentencia C-355 de 2006 y es su obligación remitir inmediatamente a la mujer embarazada a un profesional de la salud que pueda practicar dicho procedimiento.

En tal virtud se ha condenado a instituciones promotoras y prestadoras de salud, EPS e IPS y a profesionales de la salud que atienden casos y no obran de conformidad con las obligaciones 
derivadas de los fallos ${ }^{10}$, a pagar los perjuicios causados a quienes soliciten la interrupción del embarazo, de acuerdo a lo establecido en la sentencia C-355-06 de esta misma Corte, por la violación de sus derechos fundamentales. ${ }^{11}$ Actualmente estas condenas son materia de controversia, por el carácter coercitivo que se le ha impuesto a la sentencia, ignorando por completo las decisiones institucionales que una entidad de salud pueda tomar en sentido a esta sentencia, afectando de manera directa a aquellas de carácter eclesial, el caso más sobresaliente ha sido el del Hospital Universitario San Ignacio, perteneciente a la Compañía de Jesús y que fue sancionado por la Secretaria Distrital de Salud de Bogotá, por negarse a practicar una interrupción voluntaria del embarazo. ${ }^{12}$

Es menester señalar la consideración final que hace la Corte Constitucional al Congreso de la República de Colombia de que pueda determinar que tampoco se incurra en delito de aborto en otros casos adicionales, acorde con la potestad de configuración legislativa de ese ente hacedor de Leyes, declarando:

En esta sentencia, la Corte se limitó a señalar las tres hipótesis extremas violatorias de la Constitución, en las que,

10 Las condenas se han establecido en casos de omisión de la obligación de remitir inmediatamente a la mujer embarazada a un profesional de la salud que pueda practicar dicho procedimiento, cuando el profesional se ha declarado impedido por objeción de conciencia.

11 Entre los Derechos fundamentales a los que hace referencia la sentencia están: la dignidad humana, la autonomía individual y el libre desarrollo de la personalidad.

12 Es importante reseñar la declaración del Director General del Hospital respecto a la sanción otorgada por la Secretaria de Salud "Un Estado como el colombiano, multiétnico, pluricultural, centrado sobre la dignidad humana, debe también procurar respeto por la dignidad de las instituciones y de las decisiones que se toman de manera autónoma, con base en principios, valores y declaraciones misionales que fundamentan la administración moderna." Julio César Castellanos Md. El derecho a decir No. Eltiempo.com. Editorial-opinión. 18 de mayo de 2009 http://www. eltiempo.com/archivo/documento/MAM-3448947 con la voluntad de la mujer y previo el cumplimiento del requisito pertinente, se produce la interrupción del embarazo. Sin embargo, además de estas hipótesis, el legislador puede prever otras en las cuales la política pública frente al aborto no pase por la sanción penal, atendiendo a las circunstancias en las cuales éste es practicado, así como a la educación de la sociedad y a los objetivos de la política de salud pública. (CORTE CONSTITUCIONAL: C 355-06)

Es esta situación la que conduce a abrir aun más el camino a la eugenesia negativa, al abrirse la ancha rendija en la distinción de la vida y su bien jurídico y el derecho a la vida del neonato, permitiéndose el aborto en todas las circunstancias de acuerdo al libre desarrollo de la personalidad de la mujer, sus derechos sexuales y reproductivos actualmente amparados en los tres casos despenalizados por la jurisprudencia en mención. En la medida que el legislador deje inmerso en el ordenamiento jurídico la despenalización total del mismo, se seleccionaría y desconocería aun más el estatus y humanidad del embrión y el feto humano, condenando a los más pobres, los afro-colombianos y las etnias indígenas a un exterminio masivo a consecuencia de la legalización del aborto. (ZÁRATE: 2005)

Retos sobre la aplicación de la objeción de conciencia institucional frente a las tres hipótesis de despenalización del aborto

Existe multiplicidad de retos sobre la objeción de conciencia institucional de las personas jurídicas prestadoras del sistema de seguridad social frente a los tres casos excepcionales de despenalización del aborto. ${ }^{13}$,

13 El S. J. Alfonso Llano Padre de la Bioética en Colombia, expresó que la persona tiene derecho a anteponer su conciencia por sus principios garantizada por el Artículo 18 constitucional que garantiza la libertad de. Aun por encima del Papa como expresión de lo vinculante hay que respetar la conciencia. Los principios y criterios no hay que revelarlos. A juicio del padre llano la objeción 
Si analizamos el alcance y contenido del artículo 18 de la Carta Política que dice:

"Artículo 18. Se garantiza la libertad de conciencia. Nadie será molestado por razón de sus convicciones o creencias ni compelido a revelarlas ni obligado a actuar contra su conciencia."

El constituyente de 1991 en ese artículo estableció tres dimensiones de esa libertad de conciencia:

\section{Una prerrogativa de No acoso ni de persecución.}

\section{Una prerrogativa de No revelarlas.}

\section{Una prerrogativa de No actuar con- tra la conciencia.}

De allí nace el derecho fundamental a la objeción de conciencia. ${ }^{14}$

Ni la Constitución ni la ley pueden estar por encima de la conciencia. La persona debe vivir de acuerdo a su conciencia o pensamiento filosófico. Este es un derecho sacro derecho a

vale no solo de la persona sino la institución como tal. Vale para las instituciones cuando dice nadie es nadie....Un hospital o clínica tiene derecho a presentar objeción de conciencia. La corte jurisprudencialmente debe aclarar lo de la objeción de conciencia. Foro sobre "objeción de conciencia institucional," organizado por ANALBE en la Universidad Militar Nueva Granada, Bogotá Colombia, 23 de septiembre de 2010

14 "La objeción de conciencia es un derecho fundamental no es un regalo ni concesión. El constituyente de 1991 estableció que el derecho a la libertad de conciencia comprendía estas tres dimensiones y la Corte la contempla así de igual manera y la diferencia de la libertad de pensamiento y la libertad religiosa.

La Corte ha entendido que tiene entre tiene su asidero en el derecho internacional. En primer lugar Convención americana sobre derechos humanos y en el Pacto de derechos civiles". José Ignacio Pretelt. Foro sobre "objeción de conciencia institucional," organizado por ANALBE en la Universidad Militar Nueva Granada, Bogotá Colombia, 23 de septiembre de 2010. la libertad moral ideológica y el libre desarrollo de la personalidad. ${ }^{15}$

Si examinamos el derecho comparado encontramos que en Francia las personas jurídicas que hacen parte del sistema de salud pueden objetar en conciencia únicamente los médicos y las instituciones privadas, más no las de carácter público.

En España el Estado no obliga a instituciones prestadoras de salud por objeción de conciencia a que violen sus propios estatutos tal como lo contempla la reciente ley de plazos para la práctica del aborto.

Al respecto en la sentencia T-388 de 2009 el Magistrado Juan Carlos Henao aclaró el voto manifestando: "En Francia se diferencian los hospitales públicos y los privados: los primeros no pueden objetar en conciencia, los segundos si. La objeción de conciencia está en los tratados suscritos por Colombia". (HENAO: 2009)

15 "La objeción de conciencia es de manera individual o colectiva. Los derechos de las personas jurídicas así lo establece la Corte interamericana de derechos humanos. Cual es el objeto de la objeción de conciencia hay conciencia ética o religiosa o filosófica. Las asociaciones fundaciones tienen socios. La asociación sirve por las personas físicas que la conforma y conlleva un ideario institucional. Al Revisar los estatutos están dispuestas hacer o no hacer. Un director de hospital es un profesional tiene derecho a la objeción de conciencia. El Estado tiene que justificar porque obliga a una determinada persona y por qué no tiene métodos alternativos para ello. El Estado está al servicio de la persona Las potestades no son limitadas. El Estado está a favor de las personas. La objeción de conciencia es un derecho humano para negarse a un acto o cooperar obligado por norma individual porque contradice sus creencias. La objeción de conciencia es para no cooperar. No es solamente al médico sino a los profesionales de la salud que son participes. El problema de la objeción de conciencia es más amplio. La persona no busca que se deroga la norma sino que no se le aplique."Fernando Toller. Académico gestor sobre el actual proyecto de ley sobre objeción de conciencia en Argentina. Foro sobre "objeción de conciencia institucional," organizado por ANALBE en la Universidad Militar Nueva Granada, Bogotá Colombia, 23 de septiembre de 2010. 
El Magistrado Henao dice que se asocian las personas con sus propósitos y pueden fundar clínicas privadas y la defensa de sus creencias es protección de libertad de conciencia de sus miembros.

Los titulares en Colombia sobre la objeción de conciencia son solamente las personas particulares o naturales. La jurisprudencia la negó para las jueces por estar sometidos al imperio de la ley. La sentencia T- 388 de 2009, dice que su estudio debe ser más estricto. Tienen deber de propender por el ordenamiento jurídico con unas connotaciones especiales. Es decir, que estos funcionarios públicos tienen sumisión al ordenamiento jurídico y por ende las connotaciones son distintas.

La Corte debe hacer esa distinción entre personas jurídicas publicas y privadas y dentro de las privadas aquellas que tengan en su ideario estatutos, posiciones en esa materia no pueden ser obligadas hacer interrupción voluntaria del embarazo; es el legislador, de acuerdo con ley quien debe pronunciarse con un contenido de principios y criterios generales y le compete a cada Juez en cada caso concreto, establecer la objeción de conciencia con prudencia jurídica y de la misma manera la Corte Constitucional debe realizar la ponderación cuando hay coalición de derechos fundamentales y debe reconocer la objeción de conciencia a personas jurídicas que profesen una ideología diferente sobre estos tópicos. (PRETELT: 2010)

Con el propósito de coadyuvar a la solución de las implicaciones sobre la objeción de conciencia, el actual Procurador General de la Nación, Alejandro Ordoñez, ha dado a conocer en el ámbito académico de la Universidad Militar Nueva Granada, el proyecto de ley que pondrá a consideración del Congreso al inicio del periodo legislativo de 2011, atinente a los ámbitos sanitario, educativo, del ejercicio de las funciones públicas y de las instituciones públicas, privadas, por creencias y convicciones religiosas o no, contemplando:

Toda persona jurídica puede objetar su conciencia por ideario institucional y debe regularse ante el Congreso. La puede establecer el representante legal. No se debe restringir. Si en el derecho constitucional y comparado se tiene derecho fundamental presentar tutela para el debido proceso, derecho penal comparado se considera que las personas jurídicas pueden cometer delitos tienen códigos éticos y de valores. (ORDOÑEZ: 2010)

Dándole alcance el mencionado Procurador a las sentencias C- 355 de 2006 y T-388 de 2009 expresó que estamos en una "democracia esquizofrénica." "Se le permite a la persona pensar como quiera y se le impide actuar como piensa". (ORDOÑEZ: 2010)

El filósofo Guillermo Hoyos disiente de la objeción de conciencia de las entidades confesionales y establece que en en nuestro Estado social de derechos cuando el artículo 18 habla de "Nadie será molestado por sus creencias, ni compelido a revelarlas, ni obligado a actuar contra su conciencia", se refiere a la persona natural en razón de que las personas jurídicas no tienen conciencia, y el camino es declarar en esos casos la desobediencia civil por parte de las personas jurídicas que predican creencias en sus estatutos como un medio para reafirmar el vínculo entre la sociedad civil cuando quedan agotadas otras vías. (HOYOS: 2010)

\section{CONCLUSIONES}

En este orden de ideas teniendo en cuenta la ambigüedad de la norma constitucional que permite a los que están a favor o en contra del aborto colegir que están amparados en la Carta Magna, no sólo desde el punto de vista individual sino de Las instituciones en comento, trátese del director general de una clínica, quien puede expresar con base al ideario de su derecho de asociación su disentimiento, dentro del personal sanitario, no solamente los médicos sino las enfermeras, instrumentadoras 
$\mathrm{u}$ otros profesionales de la salud pueden presentar objeción de conciencia, aunque la Corte Constitucional los haya dejado de lado.

En efecto, es preocupante por el alcance y contenido de la sentencia en estudio la discriminación a la que se verían avocados los médicos que expresan su objeción de conciencia al inhibirse de practicar abortos, por sus creencias, convicciones éticas morales o de cualquier otra índole que no aplicarían para participar y ser clasificados en los concursos públicos y de la misma manera, los jueces por tutelas ante asuntos de la vida, salud sexual y reproductiva. Actualmente estos últimos son obligados a fallar so pena de investigación.

Todas estas circunstancias traen implicaciones bioéticas en las decisiones que deban tomar los Comités de Ética de las instituciones sanitarias y de la misma manera el bioderecho, que debe tener en cuenta la multiplicidad de criterios para plasmar normatividad sobre estos asuntos que nos ponen en la pendiente deslizante cuando se trata del reconocimiento de los derechos sexuales y reproductivos de la mujer y el desconocimiento de los del nasciturus, en virtud de que por tutela se cambió la naturaleza del delito de aborto a derecho en la C-355 de 2006 y la T-388 de 2009, reitera que el aborto es un derecho y de la misma forma el de las personas jurídicas a proceder en conciencia de acuerdo a su misión.

Haciendo acopio de lo señalado por el Magistrado de la Corte Constitucional José Ignacio Pretelt, no actuar en contra de la conciencia, hace parte del bloque de constitucionalidad de acuerdo a los tratados sobre derechos humanos. La jurisprudencia ha sido regresiva y dubitativa en la protección y el juez debe establecer si procede la objeción de conciencia y sus límites.

Por tanto la Corte Constitucional y el legislador deben repensar la objeción de conciencia en el marco de la libertad de conciencia, en el caso del aborto y la naturaleza de la objeción de conciencia institucional.
La responsabilidad por la práctica de la interrupción voluntaria del embarazo es del Estado y tiene que asegurarlo en clínicas específicas especializadas, para que no se siga midiendo con el mismo rasero a las entidades públicas y privadas agobiadas estas últimas por sanciones y cargas injustificadas, por sus creencias de no hacerlo al tener como objeto social la defensa de la vida, y sin embargo por sentencia del Juez Constitucional se les obliga a vulnerarlo. Es el legislador el que debe asumir ese reto de establecer las distinciones respecto a la objeción de conciencia como ente hacedor de leyes, de interpretarlas, reformarlas y derogarlas por mandato constitucional.

\section{BIBLIOGRAFÍA}

CARDONA, C. E. Despenalización del aborto en Colombia: un asunto de derechos humanos de las mujeres. Consultado 6 de mayo de 2007 www.actualidadactualidadcolombiana.org/ boletin.shtml?x=839

CASTRO, L. A. (2007). Arzobispo de Tunja, presidente de la Conferencia Episcopal Colombiana. Comunicado sobre el Aborto. En Una conjura contra la vida humana. Recuento histórico sobre el proceso del aborto en Colombia. Magisterio de la Iglesia. Cardenal Alfonso López Trujillo. Colombia: Editorial San Pablo.

CARDOZO C, A. (2007) Foro Nacional de Discusión sobre la perspectiva Ético Jurídica de la sentencia C-355 de 2006. Presentación en el Ministerio de la Protección Social y en la Universidad Nacional de Colombia, Red de Bioética. Bogotá, Colombia.

DE BRIGARD, A M. ROA, M. \& PALACIO, D. (2006, 14 de mayo). Lo que debe saber del fallo sobre el aborto. El Tiempo, p.p. 1-8.

DEFENSORÍA DEL PUEBLO DE COLOMBIA. (2004). El Derecho a la Salud en la Constitución, la jurisprudencia y los Instrumentos Internacionales. p. 125. 
MAYA, E. J. (2005). Aborto en circunstancias especiales es constitucional. Bogotá, Colombia: Editor Instituto de Estudios del Ministerio Público

MINISTERIO DE LA PROTECCIÓN SOCIAL. (2006). Norma técnica para la atención de la interrupción voluntaria del embarazo IVE. Bogotá, Colombia.

Profamilia. Instituto Colombiano de Bienestar Familiar, USAID, Ministerio de la Protección Social y UNFPA. (2005). Salud sexual y reproductiva en Colombia. Encuesta Nacional de Demografía y Salud. Bogotá, Printex Impresores Ltda.

ORDOÑEZ, A. (2010). Procurador General de la Nación. Foro. Objeción de conciencia institucional, organizado por ANALBE en la Universidad Militar Nueva Granada. Bogotá, Colombia.

PRETELT J. I. (2010). Foro sobre. Objeción de conciencia institucional, organizado por ANALBE en la Universidad Militar Nueva Granada. Bogotá, Colombia.

PROFAMILIA. (2005). Sexualidad y reproducción. ¿Qué derechos tienen las colombianas y colombianos?. Bogotá, Colombia.

ZAMUDIO, L. (1999). El aborto inducido en Colombia. Bogotá, Colombia: Universidad Externado de Colombia. Centro de Investigación sobre Dinámica Social, CDS.

ZÁRATE A. J. (2005). La Despenalización del Aborto en Colombia, Congreso Informe
Especial. Bogotá, Colombia.

\section{Legislación y Jurisprudencia}

CÓDIGO CIVIL COLOMBIANO

CÓDIGO PENAL COLOMBIANO

CONSTITUCIÓN POLÍTICA DE COLOMBIA. (1991).

CONVENCIÓN AMERICANA SOBRE DERECHOS HUMANOS SUSCRITA EN SAN JOSÉ DE COSTA RICA EL 22 DE NOVIEMBRE DE 1969.

CORTE CONSTITUCIONAL COLOMBIANA. (1994). Sentencia C-133.

CORTE CONSTITUCIONAL COLOMBIANA. (1994). Sentencia C-221.

CORTE CONSTITUCIONAL COLOMBIANA. (1997). Sentencia C-013.

CORTE CONSTITUCIONAL COLOMBIANA. (1997). Sentencia C-309.

CORTE CONSTITUCIONAL COLOMBIANA. (1998). Sentencia. T-516.

CORTE CONSTITUCIONAL COLOMBIANA. (2006). Sentencia C-355.

CORTE CONSTITUCIONAL COLOMBIANA. (2009). Sentencia T-388.

MINISTERIO DE LA PROTECCIÓN SOCIAL. (2006). Decreto 4444. Colombia 